\title{
The innovative journal
}

\section{Terence Goh}

President of the Singapore Association of Plastic Surgeons

Associate Editor, Archives of Plastic Surgery

AZATACA Plastic Surgery, Singapore

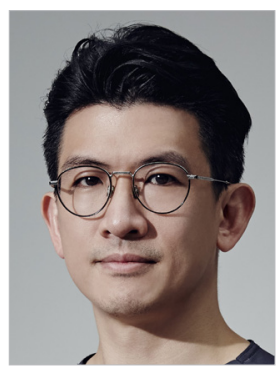

"Those that innovate the future understand history the best" Rick Warren

The Journal of the Korean Society of Plastic and Reconstructive Surgeons was first published in 1974 in the Korean language and remained so, until the journal was transformed into an English version in January 2012 when it was renamed Archives of Plastic Surgery (APS).

The main objective of this transformation was to pursue globalization by encouraging academic interaction between Asian countries and the rest of the world [1]. A concerted effort was made to invite manuscripts from the international community, with a focus on being the most representative journal for plastic surgery in Asia, whilst maintaining high publishing standards. APS is a peer-reviewed journal publishing articles in all fields of plastic and reconstructive surgery, ranging from aesthetic surgery to reconstructive microsurgery, including basic research related to all areas of plastic surgery. To ensure convenience to its readers and easy online searchability, APS remains an open-access journal allowing readers to download and view the full text of all journal content without a subscription. It is also indexed, tracked, and covered internationally by representative databases, such as PubMed, PubMed Central, CrossRef, Scopus, Embase, and Google Scholar (Fig. 1) [2].

"Innovation is the ability to see change as an opportunity-not a threat." Steve Jobs

APS has the vision of becoming the leading resource for plas- tic surgery in Asia. As part of the first step, it has tried to rally its Asian partners by inviting national academic societies to designate APS as their official journal. As of May 2021, four national societies have designated APS as their official journal: Hong Kong, Indonesia, Singapore, and Thailand. We hope that more societies will join this rally to strengthen the position of APS.

APS is harnessing the reach of social media through its ambassador program. Authors and editors are encouraged to submit videos introducing their papers on social media in order to create more opportunities to share scientific work via social media using tweets and likes. Social media activity such as tweets have been shown to either increase citations or reflect the underlying quality of the articles, which also predicts citations [3]. In this modern era, these tweets and shares will undoubtedly complement other traditional citation metrics (e.g., the impact factor) and increase the readership and status of the journal.

APS aims to stand out as the journal of plastic surgery innovation [4], by placing the innovation section ahead of the other sections. This bold move bucks the trend of most major journals that seek and publish results, especially from large clinical trials or outcome studies. However, as we all know, it is not realistic to expect many trials in a specialty with a plethora of procedures as wide and diverse as plastic surgery. Promoting innovation and ideation may seem frivolous, but it reflects the very essence of a plastic surgeon, and it is innovation that makes plastic surgery different from all other specialties.

Since APS started accepting English manuscripts in 2012, we have been regularly submitting manuscripts to the journal with good, favorable responses from the editorial team. Some of the

Copyright $(\odot 2021$ The Korean Society of Plastic and Reconstructive Surgeons

This is an Open Access article distributed under the terms of the Creative Commons Attribution Non-Commercial License (https://creativecommons.org/

licenses/by-nc/4.0/) which permits unrestricted non-commercial use, distribution, and reproduction in any medium, provided the original work is properly cited. I www.e-aps.org 


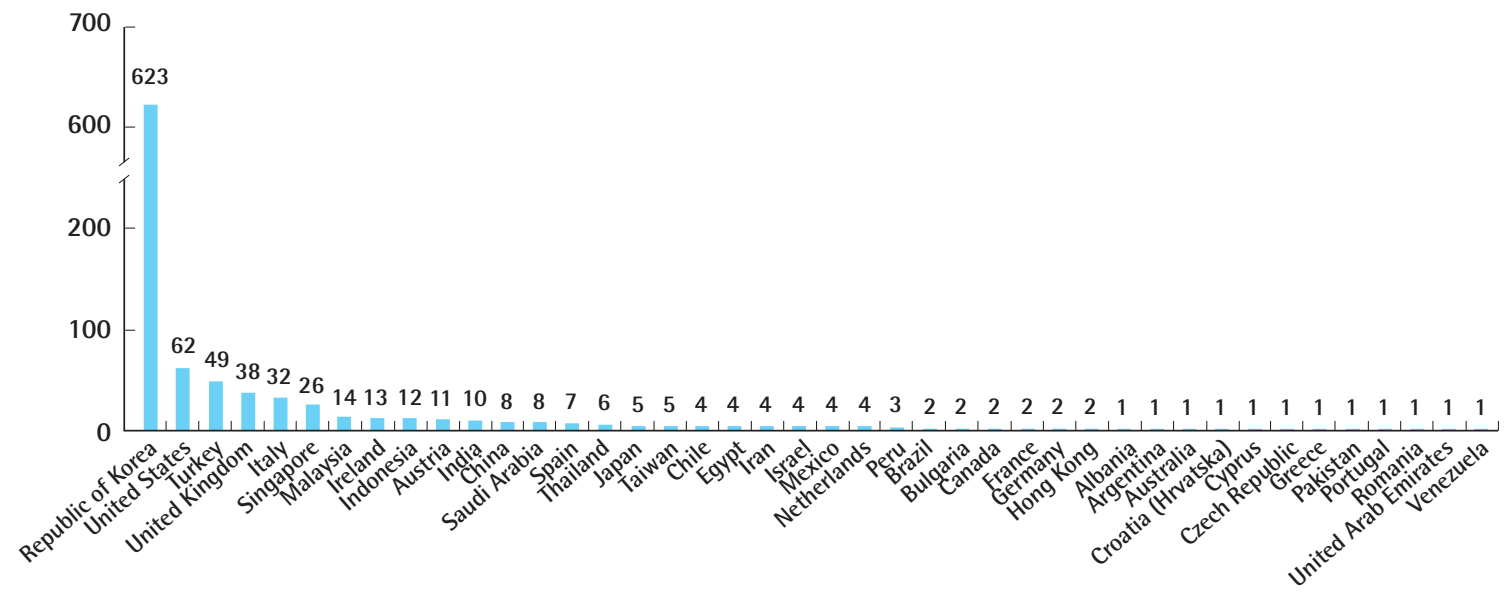

Fig. 1. Manuscript submissions to Archives of Plastic Surgery from January 2012 to May 2015 [2].

reasons cited from our members for submitting to APS include: (1) publication in English; (2) open-access publication, which promotes greater public engagement, allowing wider collaborations; and (3) the fact that the journal accepts and publishes the figures in color allowing the authors to bring their ideas across pictorially. We thank APS for the leadership and the editors for their contributions, and we look forward to greater collaboration in the years to come.

"Innovation is taking two things that exist and putting them together in a new way." Tom Freston

In conclusion, innovation builds and sustains what is good and takes the practice of today to greater heights. This is the vision of APS.

\section{NOTES}

\section{Conflict of interest}

Terence Goh is an editorial board member of the journal but was not involved in the peer reviewer selection, evaluation, or decision process of this article. No other potential conflicts of interest relevant to this article were reported.

\section{ORCID}

Terence Goh https://orcid.org/0000-0002-4013-2505

\section{REFERENCES}

1. Kim JT. Evolution to a renowned international journal. Arch Plast Surg 2012;39:1-2.

2. Kim YH. The current position of Archives of Plastic Surgery and its future. Arch Plast Surg 2015;42:387-90.

3. Eysenbach G. Can tweets predict citations? Metrics of social impact based on Twitter and correlation with traditional metrics of scientific impact. J Med Internet Res 2011;13: e123.

4. Hallock GG. Innovations: a dawning of a new age. Arch Plast Surg 2021;48:147-8.

Correspondence: Terence Go

AZATACA Plastic Surgery, Royal Square Medical Centre, Novena, Singapore 329565, Singapore Tel: +65-67788648, Fax: +65-67780649 , E-mail: drterencegoh@gmail.com

Received: May 11, $2021 \bullet$ Revised: May 12, $2021 \bullet$ Accepted: May 13, 2021

pISSN: 2234-6163 • elSSN: 2234-6171

https://doi.org/10.5999/aps.2021.00801 • Arch Plast Surg 2021;48:241-242 